\title{
Increasing Medical Student Exposure to Interventional Radiology
}

\author{
Tushar Garg ${ }^{1}$
}

Received: 10 June 2019/Accepted: 17 June 2019/Published online: 24 June 2019

(C) Springer Science+Business Media, LLC, part of Springer Nature and the Cardiovascular and Interventional Radiological Society of Europe (CIRSE) 2019

\section{To the Editor,}

I read with great interest the article by Muzumdar et al. which explores the awareness about IR in UK Undergraduate students [1]. One significant lacuna pointed out in the article is the absence of an increase in the level of knowledge about IR with an increase in seniority of the medical students. This observation leads us right towards the crux of the problem, which is the absence of formal or informal "first-time" exposure to IR. To remedy this issue, conducting an introductory lecture at the beginning of Medical School about upcoming specialties like IR will provide the much needed first exposure, upon which the students can build upon throughout their Medical School years.

As Muzumdar et al. point out in their article, the involvement of Specialty Society (like CIRSE) provides significant incentive to increase medical student participation, like scholarships to attend conferences. However, before these societies can start to have an impact, it is imperative to establish local organizations within medical schools like Interest Groups to recruit and expose the students to these opportunities. Building interest groups will provide students the opportunity to connect with the IR department in their institution, find research mentors, learn more about IR, and will give them an opportunity to themselves get involved in various things like symposiums and workshops.

\section{Compliance with Ethical Standards}

Conflict of interest Author declares no conflict of interest.

\section{Reference}

1. Muzumdar S, Dayal S, Mohamed M, Sandhu S, Singh S, Walker P. Understanding the awareness, knowledge and perceptions of interventional radiology amongst undergraduates in the UK. Cardiovasc Intervent Radiol. 2019. https://doi.org/10.1007/ s00270-019-02234-5.

Publisher's Note Springer Nature remains neutral with regard to jurisdictional claims in published maps and institutional affiliations.

Tushar Garg

gargtushark@outlook.com

1 Seth GS Medical College and KEM Hospital, Mumbai, Maharashtra 400012, India 